Deep Sea Research Part II: Topical Studies in Oceanography

November 2009, Volume 56, Issue 23, Pages 2292-

2298

http://dx.doi.org/ 10.1016/i.dsr2.2009.04.010

(c) 2009 Elsevier Ltd All rights reserved.
Archimer, archive institutionnelle de l'Ifremer http://www.ifremer.fr/docelec/

\title{
Spatial organization of a sedimentary macrobenthic community located on the West African Equatorial margin
}

\author{
Anik Brind'Amour ${ }^{a,{ }^{*}}$, Lénaïck Menot ${ }^{b}$, Joëlle Galéron ${ }^{b}$ and Philippe Crassous ${ }^{b}$ \\ a Ifremer, Département Ecologie et Modèles pour l'Halieutique, Rue de l'île d'Yeu, B.P. 21105, 44311 Nantes \\ Cedex 03, France \\ ${ }^{\mathrm{b}}$ Ifremer, Centre de Brest, Technopôle Brest-Iroise, B.P. 70, 29280 Plouzané, France \\ *: Corresponding author : Anik Brind'Amour, email address : Anik.Brindamour@ifremer.fr
}

\begin{abstract}
:
Multiscale variability of a macrobenthic community inhabiting fine sediments on the West African Equatorial margin was assessed during three cruises as part of the BIOZAIRE research program. Spatial scales ranged from 15 to $550 \mathrm{~m}$ (within station) and from 1000 to $7000 \mathrm{~m}$ (between stations). Principal Coordinates of Neighbour Matrices (PCNM) allowed the detection of multiscale patterns of variability within a location, while a binary coding of the sampling stations was used at broad spatial scales. Significant patterns were observed at 170 and $>4000 \mathrm{~m}$. The two spatial scales displayed similar biotic responses, with the Scaphopoda and Bivalvia having patterns that were opposite to the Pholoidae. A spatio-temporal patchwork of environmental variables might explain the observed patterns. Practically, these results emphasis the need to develop balanced and crossed designs among the sources of variation (geography, time, depths).
\end{abstract}

Keywords: BIOZAIRE; Habitat patches; Macrobenthic communities; Multiscale analyses; PCNM; Spatial distribution 


\section{Introduction}

According to the Organization for Economic Co-operation and Development $\left(\mathrm{OECD}^{1}\right)$, the oil demand should grow by more than $50 \%$ between 2002 and 2030, and gas demand should almost double. The oil and gas companies are now mobilizing much effort in advanced technology seeking access to new reservoirs notably in the deep offshore. With this expansion towards the deep-sea environments, follows the need to assess the ecological impacts of these activities on deep-sea sedimentary communities. One way of addressing such need is to study the distribution patterns of the macrobenthic fauna in these environments. Understanding the spatial structure and the scales of variability of these communities is necessary to develop sampling strategies and to eventually predict the response of these communities to deep-sea industrial activities.

Early and recent studies have indicated that the dispersion patterns of deep-sea sedimentary communities are not scaled-independent (Cosson et al., 1997; Jumars, 1976; Levin et al., 2001). Spatial distribution of the deep-sea macrobenthic fauna is known to be a complex system of scaleinteracting processes. For instance, at the scale of hundreds of kilometres, spatial patterns of deepsea benthic communities is commonly attributed to processes such as productivity along bathymetric and latitudinal gradients, oceanic hydrodynamics, and sediment topography. At the scale of thousands of meters, large physical structures, such as canyons, may influence the spatial distribution of the deep-sea fauna notably by providing organic supply. At the scale of centimetres (i.e. scale of a sampling core), biologically-mediated disturbances induced by food-web complexity and the activity (e.g. bioturbation) of the major deposit feeding taxa create micro-heterogeneity that influence the spatial distributions of organisms (Gerino et al. 1999).

This study pursued previous work (unpublished data) that had been carried out on the West African Equatorial margin in 2000 (Zaïango-Biol 2) and 2001 (Biozaire 2) and in which broadscale structures (at the kilometre scale) were unexpectedly identified. Additional sampling was

\footnotetext{
${ }^{1}$ OECD/IEA, 2007. All rights reserved. Last updated: 2007.
} 
1 conducted in the same area during a cruise in 2003 (Biozaire 3). Together with the data obtained

2 from the previous work, our study measured scales of spatial variability displayed by deep-sea

3 macrobenthic communities in order to improve sampling schemes for baseline studies.

4

\section{Materials and methods}

\subsection{Study area and faunal sampling}

The study area was located on the West African Equatorial margin at $1300 \mathrm{~m}$ and $1400 \mathrm{~m}$ depths $\left(11^{\circ} 30^{\prime} \mathrm{E}, 7^{\circ} 23\right.$ 'S; Fig. 1) and was visited on six occasions between March 2000 and February 2003. The present study is using data from three of these six cruises (Table 1). Sampling was carried out at four sampling stations positioned at a minimum distance of $7 \mathrm{~km}$ from exploration wells of a deep-water oil field. The stations were identified as control stations in a previous study (Sibuet et al., 2002) and were spatially organized to display multiscale distances ranging from $15 \mathrm{~m}$ (among sampling cores) to $7000 \mathrm{~m}$ (among stations).

Sampling of the macrobenthic fauna was done with an US Naval Electric Laboratory (USNEL) box corer also referred to here as core. A total of 17 cores (sampling surface of $0.25 \mathrm{~m}^{2}$ ) were used for this study (Table 1). Immediately after recovery, the sediment was sliced into 0-1 $\mathrm{cm}, 1-3 \mathrm{~cm}, 3-5 \mathrm{~cm}$, and 5-10 cm layers from the surface. Sediment was sieved on a nest of screens of decreasing mesh sizes: $1 \mathrm{~mm}, 500 \mu \mathrm{m}, 300 \mu \mathrm{m}$, and $250 \mu \mathrm{m}$. Retained fractions were preserved with $4 \%$ buffered formaldehyde in seawater. Identification of the macrobenthic fauna was carried out in the laboratory at different taxonomic levels (phylum, class, order, family). Considering that $97.7 \%$ of the fauna was located within the first five centimetres of the core, abundances from the first ten centimetres were pooled for the statistical analyses.

\subsection{Statistical analyses}

Taxa abundances were Hellinger-transformed (Legendre and Gallagher, 2001) prior to statistical analyses. The Hellinger transformation was used because it preserves the Euclidean 
1 distance among rows and thereby allows the analysis of abundance data using linear statistical

2 methods, such as redundancy analysis (RDA; Rao, 1964).

The multiscale distribution of the macrobenthic fauna was assessed at fine (within-station variability) and broad spatial scales (among-stations variability) using two analytical approaches described below. Selection of the methods was done according to the spatial covering of the samples (i.e. distance between two cores; Fig. 2).

\subsubsection{Within-station variability}

The spatial distribution of the benthic community at the fine spatial scale was described by the variability of the taxa at station $R 1$ (Fig. 2A). That station was selected based on the number ( $n$ $=8)$ and the spatial organization of the cores. The station covered $\sim 7000 \mathrm{~m}^{2}$ and the distances $(d)$ among the sample cores varied between 15 and $550 \mathrm{~m}$. The spatial distribution of the community was quantitatively described using Principal Coordinates of Neighbour Matrices (PCNM), a method developed by Borcard and Legendre (2002) and Borcard et al. (2004). The method allows the detection and quantification of spatial variability over a wide range of spatial scales detectable by the sampling design. It uses the geographical coordinates of the sampling sites to build a matrix of Euclidean distances among the sampling sites. In the present study, the matrix of distance was calculated using the geographic coordinates of the cores. The matrix of Euclidean distances was then truncated at a user-defined threshold to only retain the distances between neighbouring sites.

This threshold was set up at a distance of $50 \mathrm{~m}$, which corresponded to the largest distance between neighbouring (or: adjacent) cores at station $R 1$. That threshold also accounted for the error in the GIS positioning of the sampling gear. The other distances among cores in the matrix were replaced by an arbitrary large value, $200 \mathrm{~m}$. A principal coordinate analysis on the truncated distance matrix was computed and only the coordinates corresponding to positive eigenvalues were kept. The resulting principal coordinates (called PCNM eigenfunctions) were sinusoids describing all the spatial scales that could be observed using the sampling design of the study (Borcard and Legendre, 
1 2002). The PCNM functions were used afterward in a canonical redundancy analysis (RDA) to

2 explain the variation in taxonomic composition (response variables) among the cores. Significant

3 PCNM functions were identified by a forward selection procedure developed by S. Dray (2005) and

4 implemented in the "packfor" package in R (R Development Core Team, 2005). The procedure

5 used the results of a permutation test (999 random permutations) to test the significance of the

6 explanatory variables successively entering the model and stopped when either the contribution (i.e.

$7 \quad \mathrm{R}^{2}$ ) of a newly included variable was lower than 0.001 or the $p$-value of a newly included variable

8 was higher than an alpha threshold of 0.05 .

\subsubsection{Among-station variability}

Identification of the significant spatial structures at the broad spatial scale was done using

11 binary coding of the sampling stations (Fig. 2B). We conducted an RDA with the coding as

12 explanatory variables and the abundance of taxa as response variables. The RDA used the same

13 forward selection procedure with unrestricted permutations as described above.

\section{3. Results}

\subsection{Variability of the macrobenthic community}

A total of 19 taxa corresponding to 16428 individuals were observed. From that total, six to seven taxa made up over $50 \%$ of the total abundance every year. Although the major taxa were the same for the three years of sampling, spatial, taxonomic and temporal variability could be observed (Fig. 3). For instance, the abundances of Bivalvia decreased from 2000 to 2003 whereas the abundances of Paranoidae increased. These two taxa also indicated great spatial variability (i.e. differences among the cores) as shown by the amplitude of the standard deviation bars (Fig. 3). Altogether these results suggest that yearly punctual or exceptional events may modify the number of individuals within each taxon without affecting the overall structure of the community (i.e. relative importance of each taxon). 


\subsubsection{Multiscale spatial variability}

Spatial analyses indicated that the macrobenthic fauna varied significantly at two spatial scales: within and among the sampling stations. Quantification of the spatial pattern at the withinstation level by PCNM analysis of among the $R l$ cores produced seven sinusoid-like spatial functions describing variation at all the spatial scales (i.e. potential patterns of variability) at the station level (Fig. 4). Forward selection on these variables confirmed the significance of a single function (PCNM ${ }^{\circ} 1$ ), explaining $33.4 \%$ of the taxonomic variability among the cores. The distance between the two contrasting groups of cores was $170 \mathrm{~m}$. The contributions of the taxa to the single RDA axis produced by the spatial model at that scale, indicated opposite distribution patterns between the Pholoidae and three other taxa (the Bivalvia, Scaphopoda, and Tanaidacea; Fig. 5A). The Pholoidae were 1.9 times more abundant in the light bubbles (cores \#60 and 61) than in the dark bubbles (cores \#30 and 35), whereas the Bivalvia, Scaphopoda, and Tanaidacea showed the inverse pattern and were, respectively, 2.8, 3.0, and 1.9 times more abundant in the dark bubbles than in the light bubbles (Fig. 5B). It is noteworthy mentioning that the observed spatial differences in the cores could also be interpreted temporally. The cores displaying spatial differences also differed in sampling years because the sampling design confounded the spatial and temporal variations. Therefore, although the statistical analyses focused on spatial variability, spatial variability cannot be separated from the temporal variability. It would indeed be more appropriate to refer to spatio-temporal variability at this scale of observation (within-station scale).

The among-stations RDA, which used the binary-coded stations as explanatory variables, brought out the differences associated with among-station variation. The main factor was the difference between station $R 2$ and the three other stations: canonical axis 1 accounted for $17.2 \%$ of the total taxonomic variation among the cores (Fig. 6A). Located $100 \mathrm{~m}$ deeper than the other stations, $R 2$ was between 4 and $7 \mathrm{~km}$ from the other stations. As indicated by Fig. 6B, the Scaphopoda and Bivalvia were, respectively, 2.2 and 1.9 times more abundant in $R 2$ than in the 
1 other stations. Three Polychaetes families (Cirratulidae, Glyceridae, and Pholoidae) showed the

2 opposite pattern: they were, respectively, 1.8, 2.1, and 1.5 more abundant in the other stations in comparison to $R 2$. Although associated with depth, the spatial distribution of these macrobenthic taxa cannot be exclusively interpreted in that context because no other station was located on the same isobath as $R 2$ and hence the station is confounded with the bathymetry effect.

\section{Discussion}

\section{Multiscale spatio-temporal patterns}

Spatial structures of macrobenthic communities were apparent at two spatial scales envisioned in this study. At the fine spatial scale, the analysis indicated a significant pattern mainly between two groups of cores at station $R 1$. Within each group, the core-to-core spacing (i.e. distance among ) ranged between $15 \mathrm{~m}$ and $85 \mathrm{~m}$ whereas the groups displayed a geographical distance of $170 \mathrm{~m}$ from each other. The two groups were composed of cores sampled at two different years, thereby preventing any conclusions regarding the relative importance of the spatial versus the temporal variability. Whether the distribution was patchy, temporally dynamic, or both, our study showed that the abundance of the dominant macrobenthic taxa was variable over relatively short spatio-temporal scales on the upper slope of the Angolan margin.

At the broad spatial scale, structure of the macrobenthic communities differed among stations located at $1300 \mathrm{~m}$ and $1400 \mathrm{~m}$ depth corresponding to distances ranging between 4 and 7 $\mathrm{km}$. That pattern was consistent through time, in the sense that cores taken at $1300 \mathrm{~m}$ depth in 2000 and 2003 were different from the cores taken in 2000 but at a different depth (1400 m).

21 Unfortunately, due to logistic limitations (e.g. ship time), it was not possible to sample core replicates at both isobaths and therefore the sampling was confounding geography, time, and depth.

23 While we are aware that the sampling design deviated from the ideal crossed and balanced situation 24 (small sample sizes and low sensitivity), our results (e.g. the similarities in biotic responses between the two analyses), interpreted in the broader scope of the BIOZAIRE research program, may 
1 help in identifying processes contributing to the highlighted multiscale patterns of the sedimentary macrobenthic fauna.

\section{Similar biotic responses at two different scales}

At each spatial scale, the abundances of Bivalvia and Scaphopoda were inversely related to the abundances of Pholoidae. The consistent covariance among these taxa at the two spatial scales may be explained either by (i) a misinterpretation of the results due to the low taxonomic resolution of the data, i.e. we may have misinterpreted the response as being from a single "species" while in fact the biotic responses from the same taxa were from different species, (ii) variation in community structure was generated by similar causes at both spatial scales, or (iii) different causes at different scales generated similar biotic responses. The first hypothesis can likely be withdrawn

11 for the Pholoidae because all the individuals observed in our study belonged to a single morphospecies of the genus Pholoe. The second and the third hypotheses are somehow more difficult to sort out because the study was not designed to test such hypotheses. Nevertheless, given the ubiquity of the three taxa and based on the results from other studies in the BIOZAIRE program (in this volume), evidences tend to support the hypothesis that variations in the community structure may have had similar causes at both spatial scales. We suggest that the observed multiscale patterns may have been caused by the spatially dynamic patchwork of the environmental conditions prevailing in the study area. The following section explains the rational of this hypothesis.

Spatio-temporal "patchwork” of environmental conditions

The Pholoidae are small polychaetes, presumably carnivorous (Fauchald and Jumars, 1979), which ranked third among the dominant polychaete families on the upper slope of the Angolan margin. As mentioned previously, all the individuals in our samples belonged to the genus Pholoe.

24 This morphospecies was also among the dominant taxa in the control colonization trays of enrichment experiments (Menot et al., this volume). During these experiments, the abundance of 
1 Pholoidae was subject to interannual variability associated with the variability of natural inputs of

2 organic matter. The recruitment for this species thus seems to be enhanced by episodic pulse of

3 organic enrichment.

Aside from the particular case of colonization trays, both temporal and spatial variations in organic matter inputs affect the whole Angolan margin (Rabouille et al., this volume). Temporal

6 fluctuations for vertical fluxes of particulate organic matter were reported from long-term

7 pluriannual sediment trap measurements. Spatial variations were also observed in diffusive and total oxygen uptake measurements. Furthermore, currents on the upper slope of the Angolan margin are high (up to $20-30 \mathrm{~cm} / \mathrm{s}$ at $30 \mathrm{~m}$ above bottom) and variable in strength and they mainly oscillate along the slope, with a south-eastward residual (Vangriesheim et al., 2005). Thus the strength and direction of the currents coupled with their periodical oscillations, suggest the alternation of deposition/resuspension events in the study area (McCave et al., 1995; McPhee et al., 1998). Based on the residual current, the sediment transport in the benthic boundary layer could eventually come from the highly productive area in the vicinity of the Congo canyon (van Bennekom and Berger, 1984; Wenzhöfer and Glud, 2002), located north of our study area. This interpretation would be consistent with conclusions of Rabouille et al. (this volume), who stressed the importance of near-bottom lateral inputs to equilibrate the organic carbon mass balance between vertical POC fluxes, mineralization and burial rates.

The interactions between multiple sources of POC fluxes, laterally and vertically, the succession of sedimentation/erosion events, and the supply of young recruits are likely to produce a spatio-temporal patchwork of environmental conditions affecting the distribution and structure of macrobenthic communities. As illustrated by the pulse recruitment of Pholoidae (Menot et al., this volume) or the spatio-temporal variations of the deep macrobenthic communities downslope (Galéron et al., this volume), modifications of the macrobenthic community structure could be associated with this spatio-temporal dynamic of habitat patches, which in turn might affect the 
1 biotic interactions such as the negative covariance observed in this study. The concept of mosaic of

2 habitats was notably introduced by Grassle and Sanders (1973) as a driver for local species

3 coexistence in the deep sea. Grassle and Sanders (1973) however emphasized the role of micro-

4 succession stages at a much finer scale than those reported here. Several studies searched for spatial

5 patterns of macrobenthic communities to test this coexistence hypothesis at such fine spatial scales

6 (Jumars, 1975; Smith, 1986; Kukert and Smith, 1992; Schaff and Levin, 1994; Snelgrove et al.,

7 1994) but none of them provide strong evidence in support of the patch dynamic hypothesis

8 favouring species coexistence (Snelgrove and Smith, 2002). In this study, multivariate analyses

9 showed that the macrobenthic community on the upper slope of the Angolan margin is, to a certain

10 extent, structured in space but at broader scales than those previously envisioned by Grassle and

11 Sanders (1973). Long term measurements of POC fluxes and currents recorded during the BIOZAIRE

12 research program underlined the variability of the environmental settings, but unfortunately the

13 sampling scheme of environmental variables did not permit to identify the factors responsible for

14 the observed patterns.

\section{Implications for sampling strategies}

The primary purpose of this study was to identify spatial patterns of macrobenthic communities to provide advice on sampling schemes in baseline studies. Analysis at the scale of a sampling station displayed no significant spatial pattern below a distance of $170 \mathrm{~m}$. Considering the fine-scale dynamic nature of deep-sea benthic communities (Snelgrove et al., 1994), supplementary analyses using a finer and more regular sampling grid are thus needed before suggesting that distance as a threshold below which the cores could be considered as being autocorrelated (sensu Legendre and Legendre, 1998). This means that spatial structures observed below that threshold would be produced by the community dynamics as opposed to spatial structures above that threshold which would be environmentally induced. Therefore, sampling at a scale finer than these $170 \mathrm{~m}$ would be in a sense "useless" when identifying significant environmental variability in taxonomic composition. 
2 significant. The smallest distance between two stations displaying such differences was

3 geographically estimated to be $4000 \mathrm{~m}$. It would be ill-advised however to specify that distance as a

4 “among-station" threshold because some distances separating two stations were not replicated (e.g.

$51000 \mathrm{~m}$ ) and, as mentioned in the results section, it is difficult to separate the station effect from the

6 bathymetry effect at that scale.

7 In conclusion, it is essential when developing designs dedicated to baseline studies, to

8 include several control stations (and replicates within stations) at different depths and time and

9 conduct a balanced cross-designed survey such that the "natural" spatial variability, the temporal

10 variability, the depth variability, and their interactions could be effectively tested (Underwood, 11 1994). 
The authors would like to thank the scientists and all the crew members who conducted the

3 sampling and participated to the BIOZAIRE program. They would also like to thank M.-C. Fabri who

4 provided the maps in Fig. 1 and Fig. 2. The present study was part of a postdoctoral project done by

5 A. Brind'Amour and was financed by Total Petroleum Company (TOTAL

6 DGEP/TDO/CA/ACOMS CT n FR00000935, Réf. IFREMER Nº5/2 210 177/F). Special thanks

7 to the anonymous referee for his comments that greatly improved the manuscript.

8 


\section{References}

Borcard, D., Legendre, P., 2002. All-scale spatial analysis of ecological data by means of principal coordinates of neighbour matrices. Ecological Modelling 153, 51-68.

Borcard, D., Legendre, P., Avois-Jacquet, C., Tuomisto, H., 2004. Dissecting the spatial structure of ecological data at multiple scales. Ecology 85, 1826-1832.

Cosson, N., Sibuet, M., Galeron, J., 1997. Community structure and spatial heterogeneity of the deep-sea macrofauna at three contrasting stations in the tropical northeast Atlantic. Deep-Sea Research I 44 (2), 247-269.

Dray, S., 2005. Packfor: Forward selection with multivariate Y by permutation under reduce model. www.steph280.freesurf.fr/

Fauchald, K., Jumars, P.A., 1979. The diet of worms: a study of polychaetes feeding guilds. Oceanography and Marine Biology Annual Review 17, 193-284.

Galéron, J., Menot, L., Renaud, N., Crassous, P., Khripounoff, A., Treignier, C., Sibuet, M., Spatial and temporal patterns of deep-sea macrofaunal communities in the Gulf of Guinea. Deep-Sea Research II. (this volume)

Gerino, M., Stora, G., Weber, O., 1999. Evidence of bioturbation in the Cap-Ferret Canyon in the deep northeastern Atlantic. Deep-Sea Research II 46 (10), 2289-2307.

Grassle, J.F., Sanders, H.L., 1973. Life histories and the role of disturbance. Deep-Sea Research 20, 643-659.

Jumars, P.A., 1975. Environmental grain and polychaete species diversity in a bathyal benthic community. Marine Biology 30, 253-266.

Jumars, P.A., 1976. Deep-Sea species diversity: does it have a characteristic scale? Journal of Marine Research 34 (2), 217-246.

Kukert, H., Smith, C.R., 1992. Disturbance, colonization and succession in a deep-sea sediment community: artificial-mound experiments. Deep-Sea Research 39 (7/8), 1349-1371.

Legendre, P., Gallagher, E.D., 2001. Ecologically meaningful transformations for ordination of species data. Oecologia 129 (2), 271-280.

Legendre, P., Legendre L., 1998. Numerical Ecology, Second English edition. Amsterdam: Elsevier Science BV. 
1 Levin, L.A., Etter, R.J., Rex, M.A., Gooday, A.J., Smith, C.R., Pineda, J., Stuart, C.T., Hessler, R.H., Pawson, D., 2001. Environmental influences on regional deep-sea species diversity. Annual review of Ecology and Systematics 32, 51-93.

McCave, I.N., Manighetti, B., Robinson, S.G., 1995. Sortable silt and fine sediment size/composition slicing: Parameters for palaeocurrent speed and palaeoceanography. Paleoceanography 10, 593-610.

McPhee, E.E., Nowell, A.R.M., Sternberg, R.W., 1998. Boundary layer measurements and their implications for sediment transport on the eastern Norwegian Sea continental slope. DeepSea Research I 45 (4-5), 719-743.

Menot, L., Crassous, P., Desbruyeres, D., Galéron, J., Khripounoff, A., Vangriesheim, A., Sibuet, M., this voume. Bathyal versus abyssal macrobenthic colonization patterns on the Angolan margin (SE Atlantic). Deep-Sea Research II. (this volume)

Rabouille, C., Caprais, J.C., Lansard, B., Crassous, P., Dedieu, K., Reyss, J.L., Khripounoff, A., this volume. In situ measurements of oxygen consumption and organic matter budget in the Southeast Atlantic continental margin close to the Congo Canyon. Deep-Sea Research II. (this volume)

Rao, C.R., 1964. The use and interpretation of principal component analysis in applied research. Sankhya Serie A 26, 329-358.

Schaff, T.R., Levin, L.A., 1994. Spatial heterogeneity of benthos associated with biogenic structures on the North Carolina continental slope. Deep-Sea Research II 41, 901--918.

Sibuet, M., Galeron, J., Khripounoff, A., Menot, L., Olu-Le Roy, K., Durrieu, J., Miné, J., Caprais, J.C., Crassous, P., Fabri, M.C., Vangriesheim, A., Desneulin, J., Savoye, B., Cochonat, P., Ondréas, H., Etoubleau, J., Loubrieu, B., Dinet, A., Von Cosel, R., 2002. Deep-Sea ecosystems on the Equatorial African Margin: First results on a pluridisciplinary environmental programme and discovery of chemosynthetic based ecosystem. Proceedings of the Sixth international conference on health, safety \& environmental in Oil and Gas exploration and production Kuala-Lumpur, 16 p.

Smith, C.R., 1986. Nekton falls, low-intensity disturbance and community structure of infaunal benthos in the deep sea. Journal of Marine Research 44, 567-600.

Snelgrove, P.V.R., Grassle, J.F., Petrecca, R.F., 1994. Macrofaunal response to artificial enrichments and depressions in a deep-sea habitat. Journal of Marine Research 52, 345-369. 
1 Snelgrove, P.V.R., Smith, C.R., 2002. A riot of species in an environmental calm; The paradox of the species-rich deep sea. Oceanography and Marine Biology: an Annual Review 40, 311 342.

4 R Development Core Team, 2005. R: A language and environment for statistical computing. R Foundation for Statistical Computing, Vienna, Austria

Underwood, A.J., 1994. On beyond BACI: sampling designs that might reliably detect environmental disturbances. Ecological Applications 4 (1), 3-15.

Vangriesheim, A., A.M. Tréguier, and G. André (2005) Biweekly current oscillations on the continental slope of the Gulf of Guinea. Deep-Sea Research I, 52(11): 2168-2183.

van Bennekom, A.J., Berger, G.W., 1984. Hydrography and silica budget of the Angola basin. Netherland Journal of Sea Research 17, 149-200.

Wenzhöfer, F., Glud, R.N., 2002. Benthic carbon mineralization in the Atlantic: a synthesis based 13 on in situ data from the last decade. Deep-Sea Research I 49 (7), 1255-1279. 


\section{Figure captions}

2 Fig. 1 Study area located on the West African Equatorial margin along the coast of the Angola.

3 The present study was conducted in Zone A (ZA: grey square). The map is a courtesy of Ifremer (C)

4 IFREMER DRO/GM).

5 Fig. 2 Summary of the (A) within-station and (B) among-stations statistical analyses used in the 6 study.

7 Fig. 3 Mean abundance of taxa in 2000, 2001, and 2003. Vertical bars indicate the standard

8 deviation, which correspond to the spatial variability among the 17 cores.

9 Fig. 4 Bubble-plots illustrating the PCNM functions corresponding to the potential spatial scales

10 of variability based on the geographic distances among the cores at station $R l$.

11 Fig. 5 Analysis of the variability within station $R 1$. (A) Contributions of the taxa to the formation 12 of the single RDA canonical axis. The loadings along the first non-canonical axis are used to 13 produce a 2-dimensional plot instead of pointing the taxa scores along a single axis. The shaded 14 arrow above the graph indicates variation in the abundance of the taxa: the taxa located on the right display high abundance values in the cores associated with the dark-coloured bubbles in the map

16 (graph B) whereas the taxa located on the left were more abundant in the cores associated with 17 light-coloured bubbles. The size of the bubbles reflects the core scores along the canonical axis. 


\section{$1 \quad$ Tables}

2 Table 1 Core code numbers, corresponding to the three BIOZAIRE cruises, analysed in the

3 present study. The geographic locations of the stations are shown in Fig. 2.

\begin{tabular}{llll}
\hline Cruises & Years & Stations & Codes for the cores \\
\hline Zaïango-Biol 2 & 2000 & $R 1$ & $\# 04,05,06$ \\
& & $R 2$ & $\# 07,09,17$ \\
BIOZAIRE 2 & 2001 & $R 1$ & $\# 31,35$ \\
BIOZAIRE 3 & 2003 & $R 1$ & $\# 59,60,61$ \\
& & $R 1$ & $\# 62,63,64$ \\
& & $R 3$ & $\# 56,57,58$ \\
\hline
\end{tabular}

\section{4}


Fig. 1

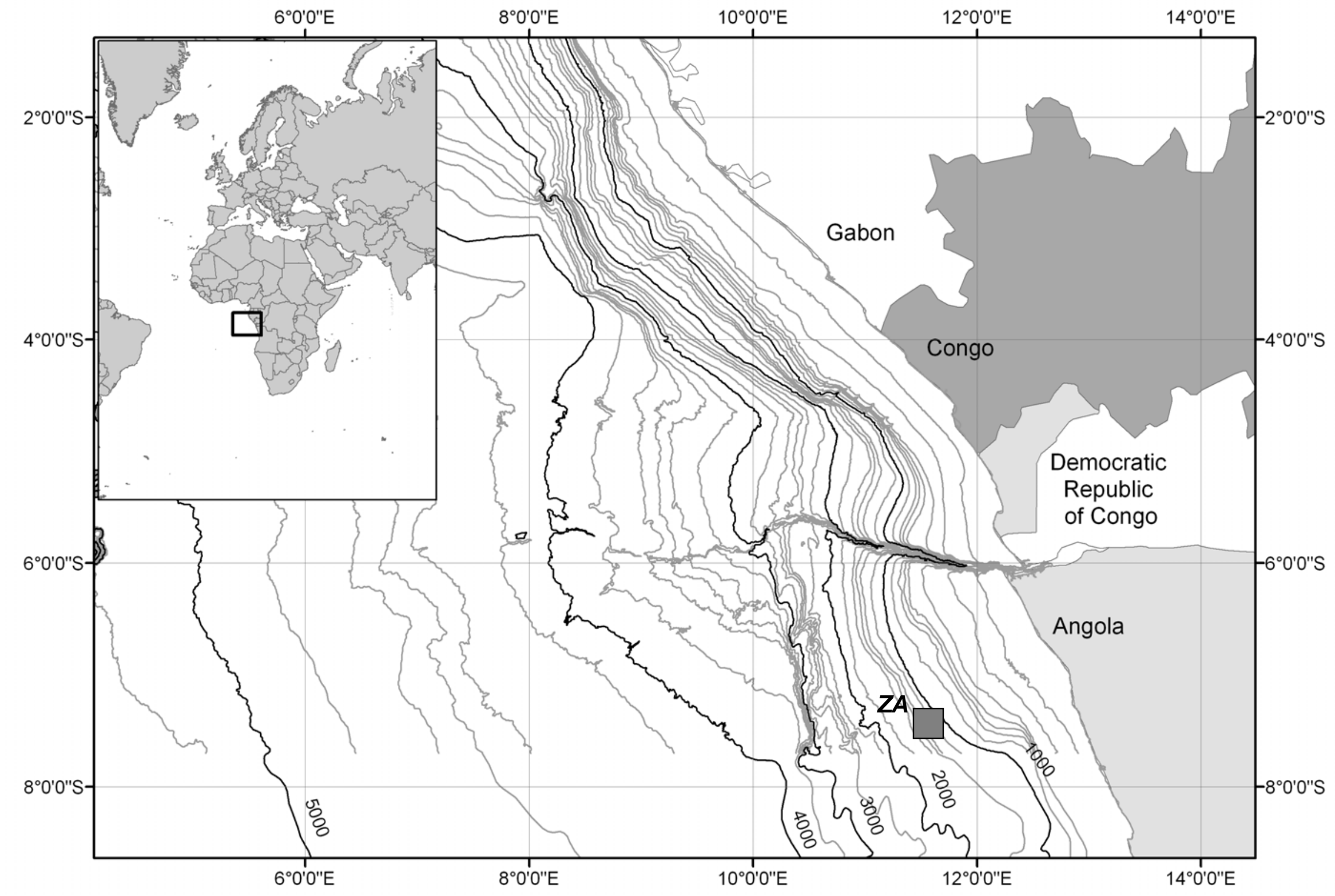


Fig. 2

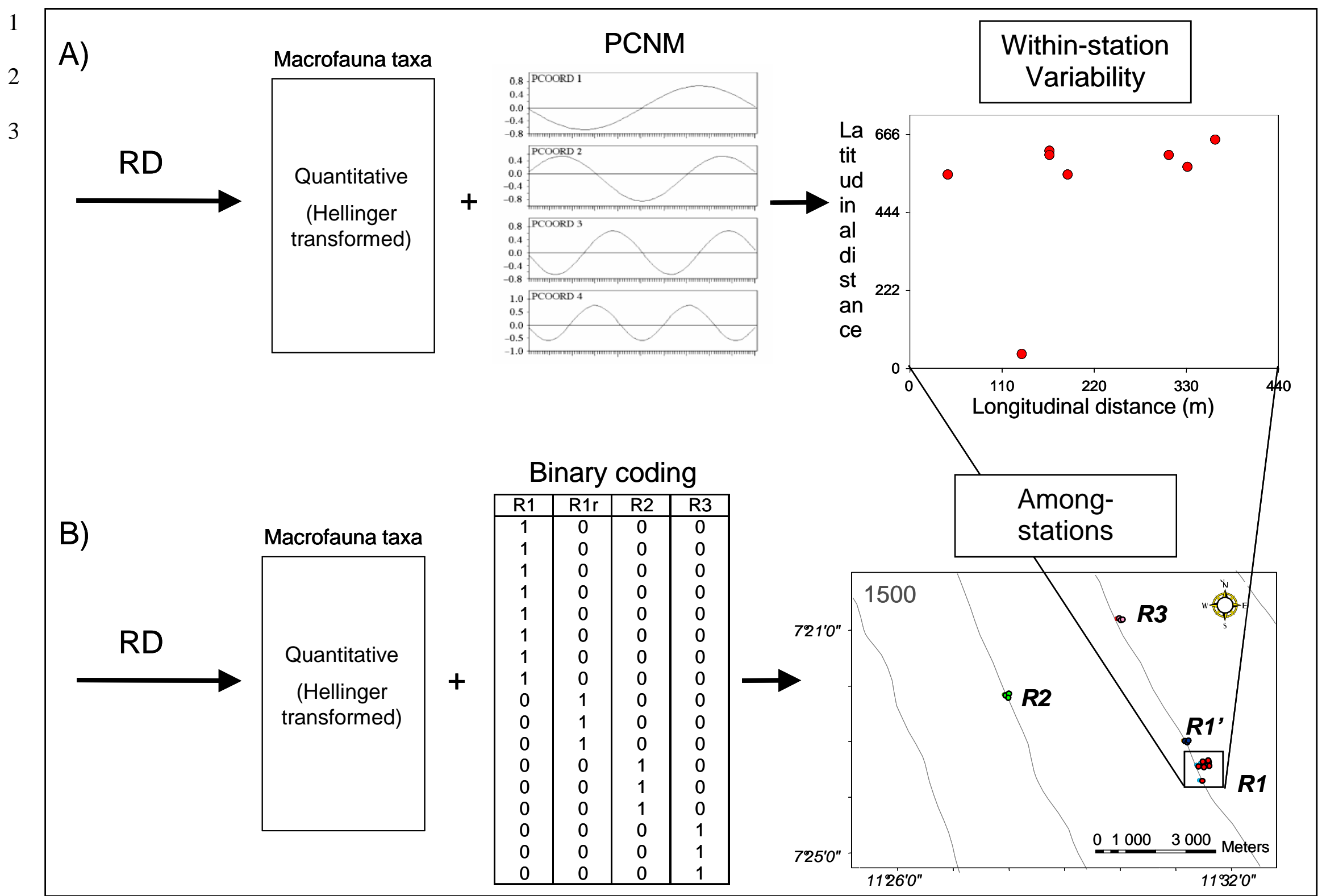


Fig. 3

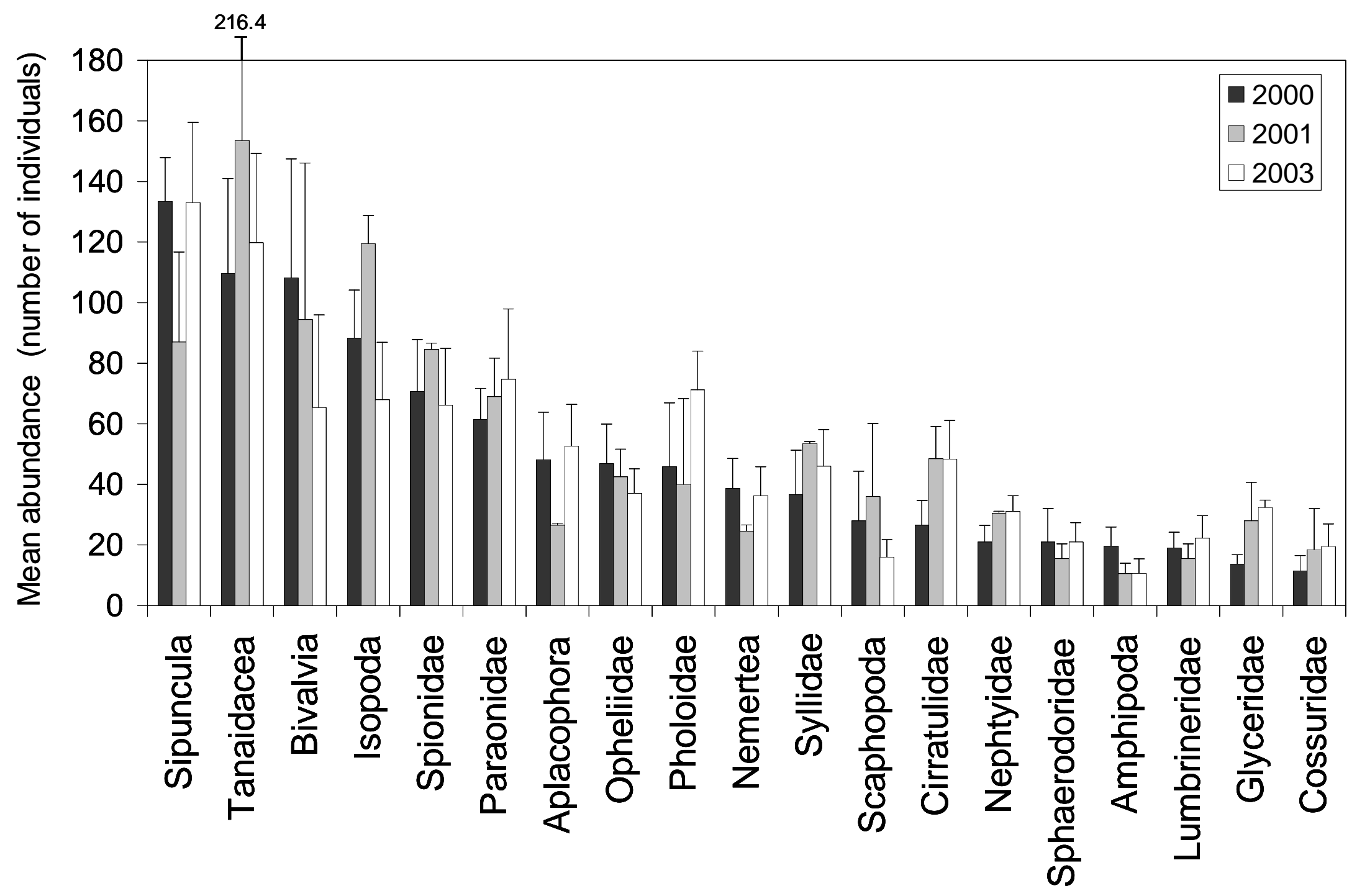


Fig. 4

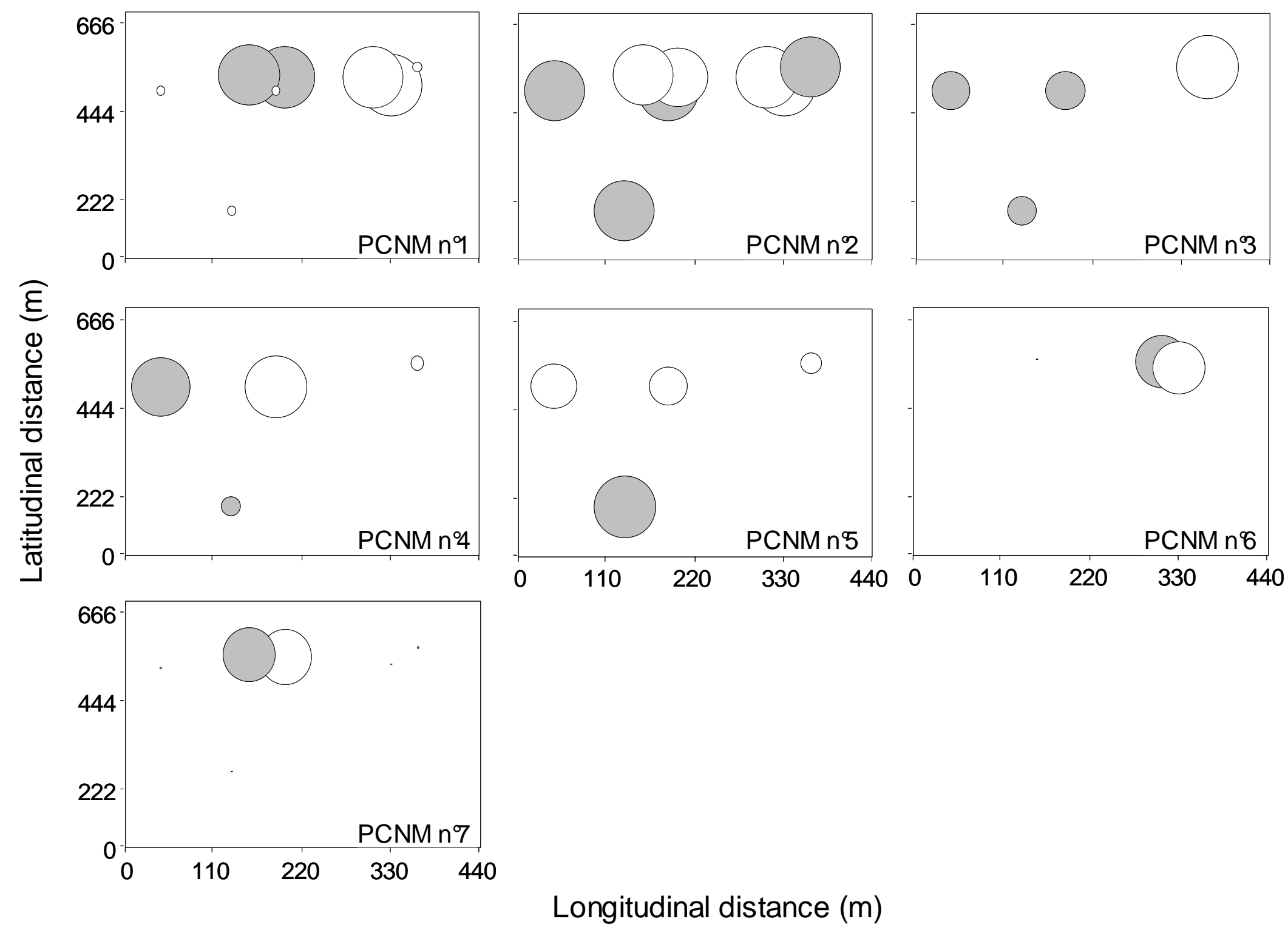


Fig. 5
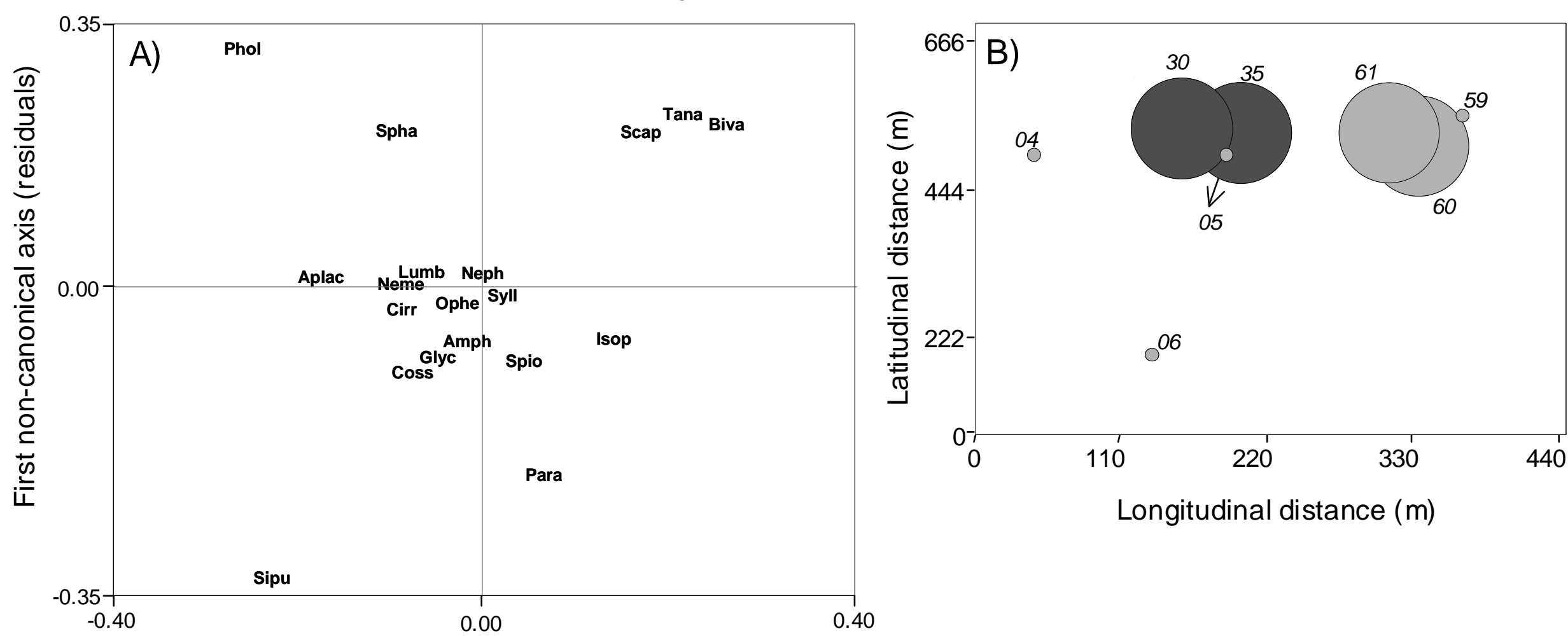

First canonical axis (33.4\%) 
Fig. 6

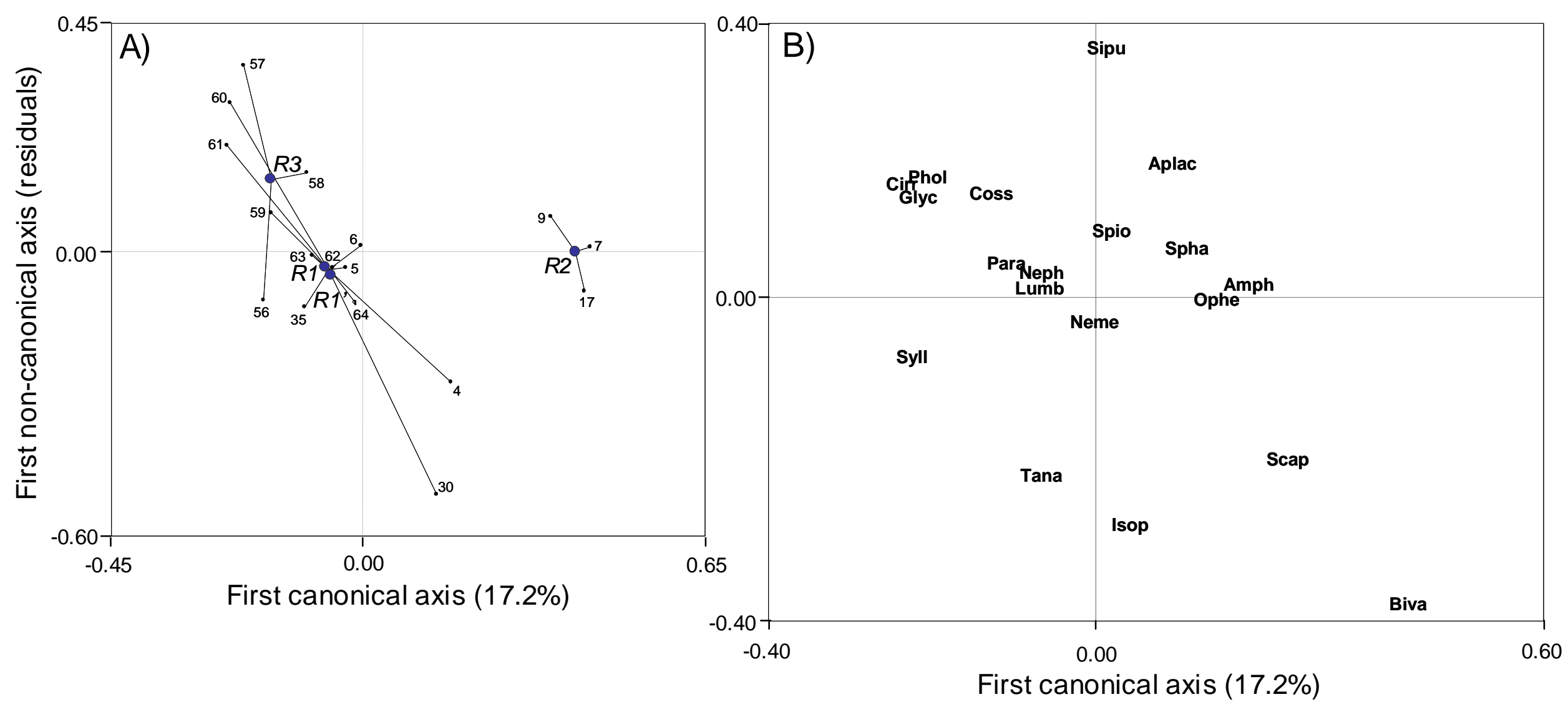

